6. Strengthening health systems resilience: key concepts and strategies. European Observatory on Health Systems and Policies website. https://www.euro.who.int/en/about-us/partners/observatory/publications/ policy-briefs-and-summaries/strengthening-health-systems-resilience-keyconcepts-and-strategies-2020. Published 2020. Accessed October 29, 2020.
7. Postgraduate School of Health Economics and Management. Analisi dei modelli organizzativi di risposta al COVID-19: Instant REPORT 15. Rome; 2020.

8. World Health Organization. Investing In and Building Longer-Term Health Emergency Preparedness During the COVID-19 Pandemic. Geneva: WHO; 2020.

\title{
Is it wise not to include hair and shoe covers in personal protective equipment (PPE) recommendations?
}

\author{
Chenyu Sun MD,MSC ${ }^{1}$ (1), Mubashir Ayaz Ahmed MD ${ }^{1}$ and Ce Cheng DO 2 \\ ${ }^{1}$ AMITA Health Saint Joseph Hospital Chicago, Chicago, Illinois and ${ }^{2}$ The University of Arizona College of Medicine at South Campus, Tucson Arizona
}

To the Editor-Coronavirus disease 2019 (COVID-19), caused by severe acute respiratory syndrome coronavirus 2 (SARS-CoV-2), has been spreading globally for more than half year. ${ }^{1}$ Healthcare workers (HCWs) on COVID-19 floors and units are aware of the higher risk of contracting SARS-CoV-2." "Routine care can be resumed only with sufficient and adequate personal protective equipment (PPE)" to protect HCWs to ensure continuous patient care during this pandemic. ${ }^{2}$ In China, $4 \%$ of confirmed cases in the first month of COVID-19 outbreak occurred among HCWs, with even higher rates in Europe due to delayed recognition of COVID-19 rather than PPE failures. ${ }^{3}$ However, the items included in PPE protocol and policies vary from institution to institution. The US Centers for Disease Control and Prevention (CDC) does not include hair covers and shoe covers in their PPE recommendations for HCWs. ${ }^{4}$

Despite the CDC not including them, hair covers and shoe covers, along with face masks, gowns, gloves, and other PPE are often used to prevent contamination from patient contact and droplets. ${ }^{1}$ A recent study suggested that the shoes of HCW might serve as a vector of SARS-CoV-2, transferring it from floors in COVID-19 rooms to floors throughout the unit. ${ }^{5}$ This is not surprising because SARS-CoV-2 contamination was common on floors in COVID-19 patient rooms. ${ }^{5,6}$ Although data on how long SARS-CoV-2 can survive on hairs, or whether it is common to have the contamination on hairs of HCWs are very limited, the virus remains viable for hours to days on different materials. ${ }^{7}$ Therefore, the potential contamination on hairs of HCWs may represent risks of nosocomial infection among non-COVID-19 patients.
We believe it is better to be cautious rather than regretful, and HCWs should be provided shoe covers and hair covers as part of PPE when providing care for COVID-19 patients. More studies will also be needed to assess the risk of contamination on human hairs as well as the efficacy of hair and shoe covers in healthcare settings.

\section{References}

1. Guddati A. Protection of healthcare professionals during an epidemic: medical, ethical, and legal ramifications. Interact J Med Res 2020;9:e19144.

2. Bresler AM, Bischoff MS, Böckler D. SARS-CoV-2-how can and must medical personnel protect themselves? Gefasschirurgie 2020;15:1-10.

3. Rhee C, Baker MA, Klompas M. The COVID-19 infection control arms race. Infect Control Hosp Epidemiol 2020. doi: 10.1017/ice.2020.211.

4. Interim infection prevention and control recommendations for healthcare personnel during the coronavirus disease 2019 (COVID-19) pandemic. Centers for Disease Control and Prevention website. https://www.cdc.gov/ coronavirus/2019-ncov/hcp/infection-control-recommendations.html. Updated July 15, 2020. Accessed September 22, 2022.

5. Redmond SN, Dousa KM, Jones LD, et al. Severe acute respiratory syndrome coronavirus 2 (SARS-CoV-2) nucleic acid contamination of surfaces on a coronavirus disease 2019 ward and intensive care unit. Infect Control Hosp Epidemiol 2020. doi: 10.1017/ice.2020.416.

6. Kim UJ, Lee SY, Lee JY, et al. Air and environmental contamination caused by COVID-19 patients: a multi-center study. J Korean Med Sci 2020; 35:e332.

7. van Doremalen N, Bushmaker T, Morris DH, et al. Aerosol and surface stability of SARS-CoV-2 as compared with SARS-CoV-1. $N$ Engl J Med 2020;382:1564-1567.

\footnotetext{
Author for correspondence: Chenyu Sun, E-mail: drsunchenyu@yeah.net

Cite this article: Sun C, Ayaz Ahmed M, and Cheng C. (2021). Is it wise not to include hair and shoe covers in personal protective equipment (PPE) recommendations?. Infection Control \& Hospital Epidemiology, 42: 1412, https://doi.org/10.1017/ice.2020.1306
}

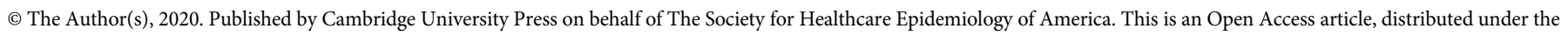
terms of the Creative Commons Attribution licence (http://creativecommons.org/licenses/by/4.0/), which permits unrestricted re-use, distribution, and reproduction in any medium, provided the original work is properly cited. 